\title{
CT angiography; useful in non-selected outpatients?
}

\author{
E. E. van der Wall · J. D. Schuijf · M. J. Schalij • \\ J. W. Jukema $\cdot$ J. J. Bax
}

Published online: 15 January 2009

(C) The Author(s) 2009. This article is published with open access at Springerlink.com

Several imaging technologies have become available for diagnostic cardiac imaging, such as single photon emission computed tomography (SPECT) [1-7], positron emission tomography (PET) [8], magnetic resonance imaging (MRI) [9-13], and coronary computed tomography angiography (CTA) [14-38]. These techniques individually offer unique advantages, but also suffer from specific limitations. CTA mainly provides anatomical information, MRI offers anatomical and functional information, whereas SPECT and PET offer metabolic and functional information. In particular gated SPECT provides functional information as this modality can be applied during conventional stress and allows the calculation of left ventricular volumes and ejection fraction. Software techniques have been developed to combine cardiac images from different modalities and generate composite multimodality images, allowing better diagnosis than obtained from images analyzed separately. Hybrid scanners (SPECT/CT and PET/CT) have also been proposed for integrated cardiac imaging.

Editorial comment to the article of Haramati et al. (doi:10.1007/s 10554-008-9382-3).

E. E. van der Wall $(\bowtie)$. J. D. Schuijf .

M. J. Schalij · J. W. Jukema · J. J. Bax

Department of Cardiology, Leiden University Medical

Center, P.O. Box 9600, Leiden, The Netherlands

e-mail: e.e.van_der_wall@lumc.nl
However, several studies have claimed that CTA as a stand-alone imaging modality may provide useful and practical information in patients with suspected and known coronary artery disease (CAD) [37-41]. Gaemperli et al. [39] showed that CTA offers a valuable alternative for the diagnosis of CAD but its value in the detection of functionally relevant coronary stenoses remains uncertain. The authors compared the accuracy of 64-slice CTA with that of myocardial perfusion imaging using perfusion SPECT as the gold standard for the detection of functionally CAD in 100 consecutive patients. Using a cut-off value of $>75 \%$ area stenosis, CTA yielded a sensitivity of $75 \%$, a specificity of $95 \%$, a negative predictive value of $93 \%$, a positive predictive value of $50 \%$ and an accuracy of $94 \%$, respectively. It was concluded that CTA is a reliable tool to rule out functionally relevant $\mathrm{CAD}$ in a non-selected population with an intermediate pretest likelihood of disease. However, an abnormal CTA proved to be a poor predictor of myocardial ischemia.

Min et al. [40] assessed the costs and clinical outcomes in individuals without known CAD who underwent CTA compared with those in matched patients who underwent myocardial perfusion SPECT. One-year CAD costs (additional diagnostic coronary testing, CAD hospitalization, and coronary procedural and revascularization costs) and clinical outcomes were examined in individuals without known CAD who underwent CTA $(n=1,647)$ compared with those who underwent myocardial perfusion SPECT $(n=6,588)$. The CTA group was less likely to 
undergo coronary angiography than the myocardial perfusion SPECT group. Adjusted CAD costs in the CTA group were $25.9 \%$ lower than in the myocardial perfusion SPECT group. Consequently, individuals without known CAD who underwent CTA as an initial diagnostic test compared with those who underwent SPECT incurred lower health care costs with similar rates of myocardial infarction and CAD-related hospitalization.

In the present issue of the International Journal of Cardiovascular Imaging, Haramati et al. [41] evaluated the utility of CTA for demonstrating CAD in inner-city outpatients. CTA was prospectively compared with stress SPECT myocardial perfusion imaging in 61 patients in an ethnically diverse, gender-balanced population. A luminal stenosis of $>70 \%$ on CTA was considered positive. Results were compared with SPECT perfusion defects and correlated with clinical endpoints (hospital admissions, cardiovascular events, coronary interventions and deaths). There was moderate global agreement of $79 \%$ between CTA and SPECT (kappa 0.483). With SPECT as the reference standard, CTA had a sensitivity of $73 \%$, a specificity of $80 \%$, a negative predictive value of $90 \%$, and a positive predictive value of $55 \%$. Eleven patients (18\%) underwent subsequent cardiac catheterization, which proved to be positive in $91 \%$ of patients. Compared with catheterization, CTA and SPECT had positive predictive values of $90 \%$ and $83 \%$, respectively.

The current study supports the value of CTA as an alternative modality for the evaluation of CAD in an ethnically diverse, gender balanced inner-city outpatient population, whereby CTA had a high negative predictive value of $90 \%$ in comparison with SPECT. Reported limitations of the study were the rather small study population, the small portion of diabetes patients $(10 \%)$, the low number of invasive angiograms (18\%), the relatively short follow-up period of 9 months, and the low event rate. Furthermore, in comparing CTA with SPECT one has to realize that SPECT perfusion imaging and CTA provide different and complementary information on CAD, namely detection of ischemia versus detection of atherosclerosis. This might explain the discordant findings in 13 patients i.e. 46 had a normal SPECT and 33 patients a normal CTA. Either a non-critical stenosis (i.e. normal CTA) may still give rise to a perfusion defect (certainly in case of a cut-off value of $70 \%$ for a critical stenosis), or a normal SPECT may occur with anatomically significant-but hemodynamically insignificant-atherosclerosis. In addition, seven patients could not be evaluated by CTA. Lastly, as the mean pretest-likelihood was rather low (30\%), the number of false positives tend to increase which may affect specificity. Nevertheless, the study of Haramati et al. [41] is a very valuable contribution to the early identification of coronary atherosclerosis in an ethnically heterogeneous group of inner-city outpatients.

Open Access This article is distributed under the terms of the Creative Commons Attribution Noncommercial License which permits any noncommercial use, distribution, and reproduction in any medium, provided the original author(s) and source are credited.

\section{References}

1. Bax JJ, Lamb H, Dibbets P, Pelikan H et al (2000) Comparison of gated single-photon emission computed tomography with magnetic resonance imaging for evaluation of left ventricular function in ischemic cardiomyopathy. Am J Cardiol 86:1299-1305

2. van der Wall EE, Heidendal GA, den Hollander W, Westera G, Roos JP (1980) I-123 labeled hexadecenoic acid in comparison with thallium-201 for myocardial imaging in coronary heart disease. A preliminary study. Eur J Nucl Med 5:401-405

3. Bavelaar-Croon CD, Pauwels EK, van der Wall EE (2001) Gated single-photon emission computed tomographic myocardial imaging: a new tool in clinical cardiology. Am Heart J 141:383-390

4. Molhoek SG, Bax JJ, Bleeker GB et al (2004) Comparison of response to cardiac resynchronization therapy in patients with sinus rhythm versus chronic atrial fibrillation. Am J Cardiol 94:1506-1509

5. Thygesen K, Alpert JS, White HD (2007) Universal definition of myocardial infarction; joint ESC/ACCF/AHA/ WHF task force for the redefinition of myocardial infarction. Eur Heart J 28:2525-2538

6. van Lennep JE, Westerveld HT, van Lennep HW, Zwinderman AH, Erkelens DW, van der Wall EE (2000) Apolipoprotein concentrations during treatment and recurrent coronary artery disease events. Arterioscler Thromb Vasc Biol 20:2408-2413

7. Bavelaar-Croon CD, Kayser HW, van der Wall EE et al (2000) Left ventricular function: correlation of quantitative gated SPECT and MR imaging over a wide range of values. Radiology 217:572-575

8. Slart RH, Bax JJ, van Veldhuisen DJ, van der Wall EE, Dierckx RA, Jager PL (2006) Imaging techniques in nuclear cardiology for the assessment of myocardial viability. Int J Cardiovasc Imaging 22:63-80

9. Holman ER, Buller VG, de Roos A et al (1997) Detection and quantification of dysfunctional myocardium by magnetic resonance imaging. A new three-dimensional method for quantitative wall-thickening analysis. Circulation 95:924-931 
10. van Rugge FP, Holman ER, van der Wall EE et al (1993) Quantitation of global and regional left ventricular function by cine magnetic resonance imaging during dobutamine stress in normal human subjects. Eur Heart J 14:456-463

11. van der Wall EE, van Dijkman PR, de Roos A et al (1990) Diagnostic significance of gadolinium-DTPA (diethylenetriamine penta-acetic acid) enhanced magnetic resonance imaging in thrombolytic treatment for acute myocardial infarction: its potential in assessing reperfusion. Br Heart J 63:12-17

12. van Dijkman PR, van der Wall EE, de Roos A et al (1991) Acute, subacute, and chronic myocardial infarction: quantitative analysis of gadolinium-enhanced MR images. Radiology 180:147-151

13. van Rugge FP, van der Wall EE, Spanjersberg SJ et al (1994) Magnetic resonance imaging during dobutamine stress for detection and localization of coronary artery disease. Quantitative wall motion analysis using a modification of the centerline method. Circulation 90:127-138

14. Juwana YB, Wirianta J, Suryapranata H, de Boer MJ (2007) Left main coronary artery stenosis undetected by 64-slice computed tomography: a word of caution. Neth Heart J 15:255-256

15. Schuijf JD, Bax JJ, van der Wall EE (2007) Anatomical and functional imaging techniques: basically similar or fundamentally different? Neth Heart J 15:43-44

16. Wijpkema JS, Dorgelo J, Willems TP et al (2007) Discordance between anatomical and functional coronary stenosis severity. Neth Heart J 15:5-11

17. van de Wal RM, van Werkum JW, le Cocq d'Armandville MC et al (2007) Giant aneurysm of an aortocoronary venous bypass graft compressing the right ventricle. Neth Heart J 15:252-254

18. de Leeuw JG, Wardeh A, Sramek A, van der Wall EE (2007) Pseudo-aortic dissection after primary PCI. Neth Heart J 15:265-266

19. Braun S, van der Wall EE, Emanuelsson S, Kobrin I (1996) Effects of a new calcium antagonist, mibefradil (Ro 40-5967), on silent ischemia in patients with stable chronic angina pectoris: a multicenter placebo-controlled study. The mibefradil international study group. J Am Coll Cardiol 27:317-322

20. ten Kate GJ, Wuestink AC, de Feyter PJ (2008) Coronary artery anomalies detected by MSCT-angiography in the adult. Neth Heart J 16:369-375

21. Henneman MM, Schuijf JD, Pundziute G et al (2008) Noninvasive evaluation with multislice computed tomography in suspected acute coronary syndrome: plaque morphology on multislice computed tomography versus coronary calcium score. J Am Coll Cardiol 52:216-222

22. Schuijf JD, Beck T, Burgstahler C et al (2007) Differences in plaque composition and distribution in stable coronary artery disease versus acute coronary syndromes; noninvasive evaluation with multi-slice computed tomography. Acute Card Care 9:48-53

23. Schuijf JD, Jukema JW, van der Wall EE, Bax JJ (2007) Multi-slice computed tomography in the evaluation of patients with acute chest pain. Acute Card Care 9:214221

24. van Werkhoven JM, Schuijf JD, Jukema JW et al (2008) Anatomic correlates of a normal perfusion scan using 64-slice computed tomographic coronary angiography. Am J Cardiol 101:40-45

25. Pundziute G, Schuijf JD, Jukema JW et al (2007) Prognostic value of multislice computed tomography coronary angiography in patients with known or suspected coronary artery disease. J Am Coll Cardiol 49:62-70

26. Schuijf JD, Pundziute G, Jukema JW et al (2006) Diagnostic accuracy of 64-slice multislice computed tomography in the noninvasive evaluation of significant coronary artery disease. Am J Cardiol 98:145-148

27. Jongbloed MR, Lamb HJ, Bax JJ et al (2005) Noninvasive visualization of the cardiac venous system using multislice computed tomography. J Am Coll Cardiol 45:749-753

28. Groen JM, Greuter MJ, Vliegenthart R et al (2008) Calcium scoring using 64-slice MDCT, dual source CT and EBT: a comparative phantom study. Int $\mathrm{J}$ Cardiovasc Imaging 24:547-556

29. de Nooijer R, Verkleij CJ, von der Thüsen JH et al (2006) Lesional overexpression of matrix metalloproteinase-9 promotes intraplaque hemorrhage in advanced lesions but not at earlier stages of atherogenesis. Arterioscler Thromb Vasc Biol 26:340-346

30. Budoff MJ, Shaw LJ, Liu ST et al (2007) Long-term prognosis associated with coronary calcification: observations from a registry of 25, 253 patients. J Am Coll Cardiol 49:1860-1870

31. Akram K, Voros S (2008) Absolute coronary artery calcium scores are superior to MESA percentile rank in predicting obstructive coronary artery disease. Int J Cardiovasc Imaging 24:743-749

32. Schenker MP, Dorbala S, Hong EC et al (2008) Interrelation of coronary calcification, myocardial ischemia, and outcomes in patients with intermediate likelihood of coronary artery disease: a combined positron emission tomography/ computed tomography study. Circulation 117:1693-1700

33. Djaberi R, Beishuizen ED, Pereira AM et al (2008) Noninvasive cardiac imaging techniques and vascular tools for the assessment of cardiovascular disease in type 2 diabetes mellitus. Diabetologia 51:1581-1593

34. Scholte AJ, Schuijf JD, Kharagjitsingh AV et al (2008) Prevalence of coronary artery disease and plaque morphology assessed by multi-slice computed tomography coronary angiography and calcium scoring in asymptomatic patients with type 2 diabetes. Heart 94:290-295

35. Bax JJ, Young LH, Frye RL et al (2007) Screening for coronary artery disease in patients with diabetes. Diabetes Care 30:2729-2736

36. Scholte AJ, Bax JJ, Wackers FJ (2006) Screening of asymptomatic patients with type 2 diabetes mellitus for silent coronary artery disease: combined use of stress myocardial perfusion. J Nucl Cardiol 13:11-18

37. Schuijf JD, Wijns W, Jukema JW et al (2006) Relationship between noninvasive coronary angiography with multislice computed tomography and myocardial perfusion imaging. J Am Coll Cardiol 48:2508-2514

38. Scholte AJ, Schuijf JD, Kharagjitsingh AV et al (2008) Different manifestations of coronary artery disease by stress SPECT myocardial perfusion imaging, coronary calcium scoring, and multislice CT coronary angiography in asymptomatic patients with type 2 diabetes mellitus. J Nucl Cardiol 15:503-509 
39. Gaemperli O, Schepis T, Valenta I et al (2008) Functionally relevant coronary artery disease: comparison of 64section CT angiography with myocardial perfusion SPECT. Radiology 248:414-423

40. Min JK, Kang N, Shaw LJ et al (2008) Costs and clinical outcomes after coronary multidetector CT angiography in patients without known coronary artery disease: comparison to myocardial perfusion SPECT. Radiology 249:62-70
41. Haramati LB, Levsky JM, Jain VR et al (2008) CT angiography for evaluation of coronary artery disease in innercity outpatients: an initial prospective comparison with stress myocardial perfusion imaging. Int $\mathrm{J}$ Cardiovasc Imaging (Epub ahead of print) 